CF. Analysis of the distribution of erythrocyte sodium-lithium countertransport in a sample representative of the general population. Genet Epidemiol 1986;3:365-78.

13 Keen $\mathrm{H}$, Chlouverakis G. An immunoassay for urinary albumin at low concentrations. Lancet 1963;ii:913-6.

14 Chantler C, Garnett ES, Parsons V, Veall N. Glomerular filtration rate measurement in man by the single method using "CrEDTA. Clin $S$ 1969;37:811-3.

15 Ryan BF, Joiner BL, Ryan TA Jr. Correlation and regression. In: Ryan BF, Joiner BL, Ryan TA Jr, eds. Minitab handbook. 2nd ed. Boston: Duxbury Press, 1985:218-36.

16 Canessa M, Adragna N, Solomon HS, Connolly B, Tosteson DC. Increased sodium-lithium countertransport in red cells of patients with essential hypertension. $N$ Engl f Med 1980;302:772-6.

17 Hilton PJ. Cellular sodium transport in essential hypertension. $N$ Engl $\mathrm{G} \mathrm{Med}$ 1986;314:222-9.

18 Williams RR, Hunt SC, Wu LL, Hasstedt SJ, Hopkins PN, Ash KO. Genetic and epidemiological studies on electrolyte transport systems in hypertension. Clin Physiol Biochem 1988;6: 136-49.

19 Erdmann E, Schmidinger U. Oubain sensitive and insensitive cation transport in normo- and hypertensives in hyperkalaemic states. In: Villareal $\mathrm{H}_{\text {, }}$ Sambhi MP, eds. Topics in pathophysiology of hypertension. Boston: Martinus Nijhoff, 1984:162-71.

20 Canessa M, Bize I, Solomon $\mathrm{H}$, et al. Na transport and co-transport in human red cells; function, dysfunction and genes in essential hypertension. Clin Exp Hypertens 1981:3:783-95.

21 Woorley RJ, Hentschell WM, Cormier C, et al. Increased sodium-lithium countertransport in erythrocytes of pregnant women. $N$ Engl $7 \mathrm{Med}$ 1982;307:412-6.

22 Brent GA, Canessa M, Dluhy RG. Reversible alteration of red cell sodium- lithium countertransport in patients with thyroid disease. $f$ Clin Endocrinol Metab 1989;68:1-7.

23 Corrocher R, Steinmayer M, Ruzzenente $\mathrm{O}$, et al. Elevation of red cell sodiumlithium countertransport in hyperlipaemias. Life Sci 1985;36:649-55.

24 Morgan DB, Stewart AD, Davidson C. Relations between erythrocyte lithium efflux, blood pressure and family histories of hypertension and cardiovascular disease. Studies in a factory workforce and a hypertension clinic. vascular disease. Studies in

25 Carr SJ, Thomas TH, Wilkinson R. Erythrocyte sodium-lithium countertransport in primary and renal hypertension and relation to family history. Eur $\mathcal{F}$ Clin Invest 1989;19:101-6.

26 Mahnensmith RL, Aronson PS. The plasma membrane sodium-hydrogen exchanger and its role in physiological and pathophysiological processes. Circ Res 1985;56:773-8.

27 Semplicini A, Spalvins A, Canessa M. Kinetics and stoichiometry of the human red cell $\mathrm{Na}+/ \mathrm{H}+$ exchanger. $f$ Membr Biol 1989;107:219-28.

28 Canessa M, Morgan K, Semplicini A. Genetic differences in lithium sodium exchanger and the regulation of sodium hydrogen exchange in essential hypertension. 7 Cardiovasc Pharmacol 1988;12 (suppl 3):S92-8.

29 Weder AB. Red cell sodium-lithium countertransport and renal lithium clearance in hypertension. $N$ Engl F Med 1986:314:198-201.

30 Smith JB, Brock TA. Analysis of angiotensin-stimulated Na transport in cultured smooth muscle from rat aorta. I Cell Physiol 1983;114:284-90

31 Li LK, Trevisan R, Walker JD, Viberti GC. Overactivity of sodium-hydrogen antiport and enhanced cell growth in fibroblasts of type 1 (insulindependent) diabetics with nephropathy [Abstract]. Kidney Int 1990;37: 199A.

(Accepted 25 fuly 1990)

\title{
Prediction of hip fracture in elderly women: a prospective study
}

\author{
R W Porter, C G Miller, D Grainger, S B Palmer
}

Abstract

Objective-To assess the relative importance of osteoporosis of the os calcis, cognisance, and mobility in the risk of subsequent fracture of the hip in elderly women.

Design-Prospective study of elderly women in residential care over two years.

Setting-21 Private or 38 local authority residential homes for the elderly and 4 geriatric hospitals in Doncaster and Hull.

Subjects-1414 Ambulant women aged over 69, in private or local authority residential care or geriatric care. Those who had had bilateral hip surgery were excluded.

Main outcome measures-Broad band ultrasonic attenuation (BUA) index, Clifton assessment procedures for the elderly test (for cognisance), and mobility on a six point scale, and fracture of the hip in the subsequent two year period.

Results - 73 Women fractured their hip during the two years. Their mean age was not significantly different from that of the women who did not have a fracture (85.3 (SD 5.6) $v 83.9(6.3) ; \mathrm{p}=0.07$ ), but their mean BUA index $(40.3(19.3) v 50.9(22.2)$ $\mathrm{db} / \mathbf{M H}_{2}$ ), and score for cognisance (median 19 (interquartile range $10 \cdot 5-27 \cdot 0) v 24(17-30)$ ) were significantly lower (both $\mathrm{p}<\mathbf{0 \cdot 0 0 1}$ ). These variables had independent associations with fracture of the hip. Women with fractures had a significantly lower score for the psychomotor component of the cognisance test $(4.5(1-8) v 7(2-10) ; p<0.0025$ and were significantly more mobile $(1(1-3) v 3(1-6) ; \mathrm{p}<0.02)$. Subdividing women according to high, medium, and low scores for BUA index and cognisance testing disclosed a high risk group (118 women) with low BUA index and cognisance score, whose incidence of fracture was $12.8 \%$; in the group at lowest risk (136 women) with high BUA index and cognisance score, the incidence of fracture was only $1.5 \%$ (relative risk $8.4(95 \%$ confidence interval -2.0 to 35.5$)$ ). Further analysis showed that those most at risk were, additionally, most mobile but that less mobile women with good cognisance had a low incidence of fractures, regardless of the BUA index, $(1 \cdot 2 \%$, high index, $v 0.9 \%$, low index).
Conclusions - Elderly women most at risk of sustaining hip fractures were those with low BUA index, low cognisance test score, and high mobility. Improving bone strength and cognisance in elderly women may reduce their incidence of hip fracture.

\section{Introduction}

About a fifth of orthopaedic beds are occupied by patients with fracture of the hip. ${ }^{1}$ The incidence has doubled in the past 25 years, and as the number of elderly people in the population continues to increase there is justifiable concern about this modern orthopaedic epidemic. ${ }^{2}$ Retrospective studies suggest that osteoporosis is a risk factor for hip fracture ${ }^{34}$ but the propensity to fall and the neuromuscular response may be equally important. ${ }^{5}$

We conducted a prospective study in a population of 1414 elderly women in residential care to assess the relative importance of osteoporosis (measured by a new ultrasound technique), cognisance, and mobility as risks for subsequent fracture.

\section{Subjects and methods}

We invited women aged 70 or above living in private residential homes or local authority homes for the elderly or in geriatric care within the catchment areas of Doncaster and Hull Royal Infirmaries to participate in the study. Women who were unable to walk with assistance and those who had had previous bilateral hip surgery were excluded.

Broad band ultrasonic attenuation (BUA) of the os calcis was used to assess osteoporosis with an Osteosonics Ultrasonic Bone Analyser $1001 .^{6}$ The foot was placed in a water bath and seated on a heel plate. An anthropometric ankle measurement ensured that the os calcis was centred between transmitting and receiving ultrasound transducers. By subtracting a water trace it was possible to measure in decibels a linear increase in ultrasonic attenuation with increasing frequency over the range 0.2 to $0.6 \mathrm{MHz}$. The rate of increase of attenuation (in $\mathrm{dB} / \mathrm{MHz}$ ) was used as the index of assessment and is referred to hereafter as the BUA index. The technique is portable, 


\begin{tabular}{|c|c|c|c|c|c|c|c|c|c|}
\hline \multirow[b]{2}{*}{ Type of residential care } & \multicolumn{3}{|c|}{ Doncaster } & \multicolumn{3}{|c|}{ Hull } & \multicolumn{3}{|c|}{ Combined } \\
\hline & $\begin{array}{c}\text { No of } \\
\text { women }\end{array}$ & $\begin{array}{l}\text { Mean }(\mathrm{SD}) \\
\text { age (years) }\end{array}$ & $\begin{array}{l}\text { No }(\%) \text { with } \\
\text { hip fracture }\end{array}$ & $\begin{array}{c}\text { No of } \\
\text { women }\end{array}$ & $\begin{array}{l}\text { Mean }(S D) \\
\text { age (years) }\end{array}$ & $\begin{array}{l}\text { No (\%) with } \\
\text { hip fracture }\end{array}$ & $\begin{array}{c}\text { No of } \\
\text { women }\end{array}$ & $\begin{array}{l}\text { Mean (SD) } \\
\text { age (years) }\end{array}$ & $\begin{array}{l}\text { No (\%) with } \\
\text { hip fracture }\end{array}$ \\
\hline Local authority & 352 & $83 \cdot 6(6 \cdot 2)$ & $23(6 \cdot 5)$ & 493 & $84 \cdot 7(6 \cdot 6)$ & $30(6 \cdot 1)$ & 845 & $84 \cdot 2(6 \cdot 5)$ & $53(6 \cdot 3)$ \\
\hline Private home & 202 & $84 \cdot 8(5 \cdot 7)$ & $6(3 \cdot 0)$ & 160 & $84 \cdot 6(5 \cdot 5)$ & $6(3 \cdot 8)$ & 362 & $84 \cdot 7(5 \cdot 6)$ & $12(3 \cdot 3)$ \\
\hline Geriatric hospitals & 189 & $81 \cdot 5(6 \cdot 4)$ & $7(3 \cdot 7)$ & 18 & $81 \cdot 0(4 \cdot 2)$ & $1(5 \cdot 6)$ & 207 & $81 \cdot 5(6 \cdot 2)$ & $8(3.9)$ \\
\hline Total & 743 & $83 \cdot 3(6 \cdot 2)$ & $36(4 \cdot 9)$ & 671 & $84 \cdot 6(6 \cdot 4)$ & $37(5 \cdot 5)$ & 1414 & $84 \cdot 0(6 \cdot 3)$ & $73(5 \cdot 2)$ \\
\hline
\end{tabular}

TABLE II - Mean (SD) BUA index and median (interquartile range) CAPE test and mobility scores in two populations of elderly women

\begin{tabular}{|c|c|c|c|c|c|c|}
\hline & \multicolumn{2}{|c|}{ Doncaster } & \multicolumn{2}{|r|}{ Hull } & \multicolumn{2}{|c|}{ Combined population } \\
\hline & $\begin{array}{c}\text { No of } \\
\text { women }\end{array}$ & Mean score & $\begin{array}{c}\text { No of } \\
\text { women }\end{array}$ & Mean score & $\begin{array}{c}\text { No of } \\
\text { women }\end{array}$ & Mean score \\
\hline BUA index $(\mathrm{dB} / \mathrm{MHz})$ & 743 & $50 \cdot 3(21 \cdot 0)$ & 671 & $50 \cdot 4(23 \cdot 5)$ & 1414 & $50 \cdot 3(22 \cdot 2)$ \\
\hline CAPE test & 591 & $25(14-30)$ & 586 & $25(14-29)$ & 1177 & $24(12-50)$ \\
\hline Mobility & 600 & $3(1-6)$ & 653 & $3(1-6)$ & 1253 & $3(1-6)$ \\
\hline
\end{tabular}

TABLE III-Mean (SD) age and BUA index and median (interquartile range) CAPE test and mobility scores in elderly women with and without hip fractures

\begin{tabular}{lcccccc}
\hline & \multicolumn{2}{c}{ Women without fractures } & & \multicolumn{2}{c}{ Women with fractures } & \\
\cline { 2 - 3 } & No of women & Score & & No of women & Score & Significance \\
\hline Mean age (years) & 1341 & $83 \cdot 9(6 \cdot 3)$ & & 73 & $85 \cdot 3(5 \cdot 6)$ & $\mathrm{p}=\mathbf{0 \cdot 0 7}$ \\
BUA index $(\mathrm{dB} / \mathrm{MHz})$ & 1341 & $50 \cdot 9(22 \cdot 2)$ & & 73 & $40 \cdot 3(19 \cdot 3)$ & $\mathrm{p}<0 \cdot 001$ \\
CAPE test score & 1116 & $24(17-30)$ & & 61 & $19(10 \cdot 5-27)$ & $\mathrm{p}<0 \cdot 001$ \\
$\quad$ Information and orientation & 1116 & $7(4-11)$ & & 59 & $5(2-9)$ & $\mathrm{p}<0 \cdot 005$ \\
$\quad$ Mental ability & 1116 & $9(7-11)$ & & 59 & $8(5-11)$ & $\mathrm{p}<0 \cdot 02$ \\
Psychomotor coordination & 883 & $7(2-10)$ & & 46 & $4 \cdot 5(1-8)$ & $\mathrm{p}<0 \cdot 0025$ \\
Mobility & 1188 & $3(1-6)$ & & 65 & $1(1-3)$ & $\mathrm{p}<0 \cdot 02$
\end{tabular}

inexpensive, and radiation free and is therefore ideal for this large epidemiological study.

Cognition was measured with the Clifton assessment procedures for the elderly (CAPE) test with its three components - namely, information and orientation, mental ability, and psychomotor coordination. ${ }^{8}$ Mobility was assessed on a scale of 1 to 6 (box).

\section{Mobility assessment scale}

1 Able to walk unaided indoors and outdoors

2 Able to walk with one stick outdoors, no aids indoors

3 Able to walk with one stick indoors

4 Able to walk with two sticks indoors

5 Able to walk with tetrapods

6 Able to walk with a frame

The assessments were made by independent examiners in each town at the place of residence, over nine months. Women who subsequently sustained a fracture of the hip were identified by visiting the orthopaedic wards of the two hospitals twice a week for a mean two year period. A visit to all the homes and geriatric wards at the end of the study was used as a final check.

Student's $t$ test was used for statistical comparisons of age and BUA index between the populations in which fractures were and were not sustained. The Mann-Whitney $U$ test was performed on the nonparametric assessments of the CAPE test and mobility score.

\section{Results}

In all, 1414 women, 743 from Doncaster and 671 from Hull, were recruited into the study. The mean ages of the populations were $83.4($ SD $6 \cdot 2)$ and 84.6 $(6 \cdot 4)$ respectively, the Hull population being signifcantly older, with a mean difference of $1 \cdot 2(95 \%$ confidence interval 0.54 to $1 \cdot 86$ ) years between the groups.

During the two year period 37 and 36 women from the Doncaster and Hull populations respectively fractured their hips. Table I shows their place of residence, mean age, and the percentage who fractured their hip. The women in geriatric hospitals were significantly younger than those in private local authority homes $(81 \cdot 5(6 \cdot 2) v 84 \cdot 2(6 \cdot 5), \mathrm{p}<0 \cdot 01)$. The BUA index, CAPE test score, and mobility score in the two populations were not significantly different (table II) and were combined to improve the statistical power of the data.

Seventy three women who subsequently fractured a hip were compared with the 1341 women who did not (table III). Those with a hip fracture were slightly older $(p=0.07)$ and their BUA index was significantly lower in the two year period $(p<0.001)$. Just over half $(52 \%)$ of the fractures occurred in women whose BUA index was below the 30th centile for the whole population. Cognisance measured by the CAPE test was also significantly poorer in the women who sustained a hip fracture $(p<0.001)$. The section of the CAPE test that measured psychomotor coordination also showed a significant difference between the two groups, women with fractures having a lower score $(\mathrm{p}<0.0025)$. The CAPE test was not assessed in some women (table III) because of deafness, poor eyesight, and other communication difficulties. The remainder were given a score if the two other parts of the test were completed. The median score for mobility was higher for the women who sustained a fracture than for those who did not (1 (range 1-3) v 3 (1-6), $\mathrm{p}<0.02$.)

The population was divided into three groups of high, medium, and low scores for BUA index and CAPE test, and the incidence of fracture of the hip was recorded in each of the nine subsets (fig 1). In the 136 women with the highest BUA index and the best cognisance incidence of fracture was only $1.5 \%$ in the two year period whereas in the 141 with the lowest BUA index and poorest cognisance the fracture incidence was $12 \cdot 8 \%$. The incidence in the 118 women with a low BUA index but good cognisance was only $3.4 \%$ and in those 130 with poor cognisance but a high BUA index $6 \cdot 2 \%$.

The BUA index and the CAPE test score were independently significant $(p=0.09)$ when a linear regression was performed on those two variables, and they were not significantly correlated $(r=0 \cdot 05)$.

The relative risk of fracture was $8 \cdot 4$ ( $95 \%$ confidence interval -2.0 to 35.5 ) between the high risk group $(12 \cdot 8 \%)$ and the low risk group $(1 \cdot 5 \%)$. Twelve fractures occurred in the 237 women who could not complete the CAPE test. The percentage of women not assessed by the CAPE test was similar in the population that did and did not sustain a fracture $16 \%$ and $17 \%$ respectively). Ten fractures occurred in the 94 women in the group with the lowest BUA index, two in the 67 women in the group with the medium index, and none in the group with the highest index. The population was further divided into the women whose scores were above and below the median for BUA index and CAPE test score who had scores for mobility above and below the median. Those women at greatest risk (incidence of 


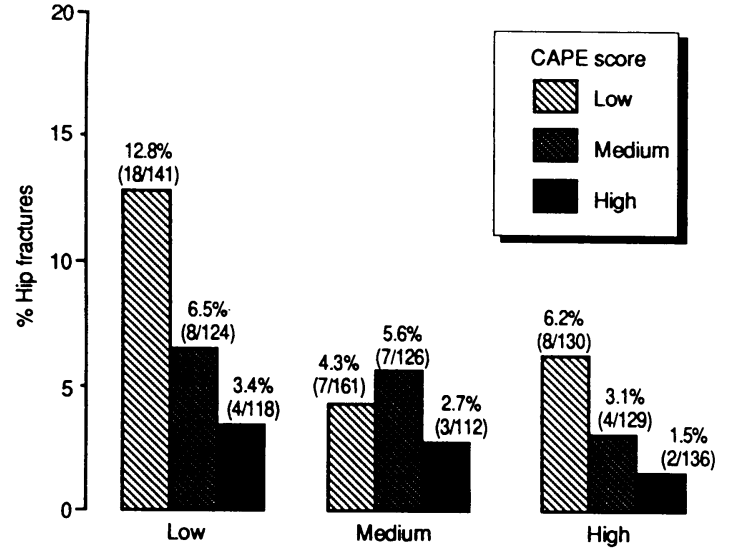

BUA index (ob/MHz)

FIG 1-Incidence of hip fractures in 1177 women according to BUA index and CAPE test score (excluding 237 women with no CAPE test score)
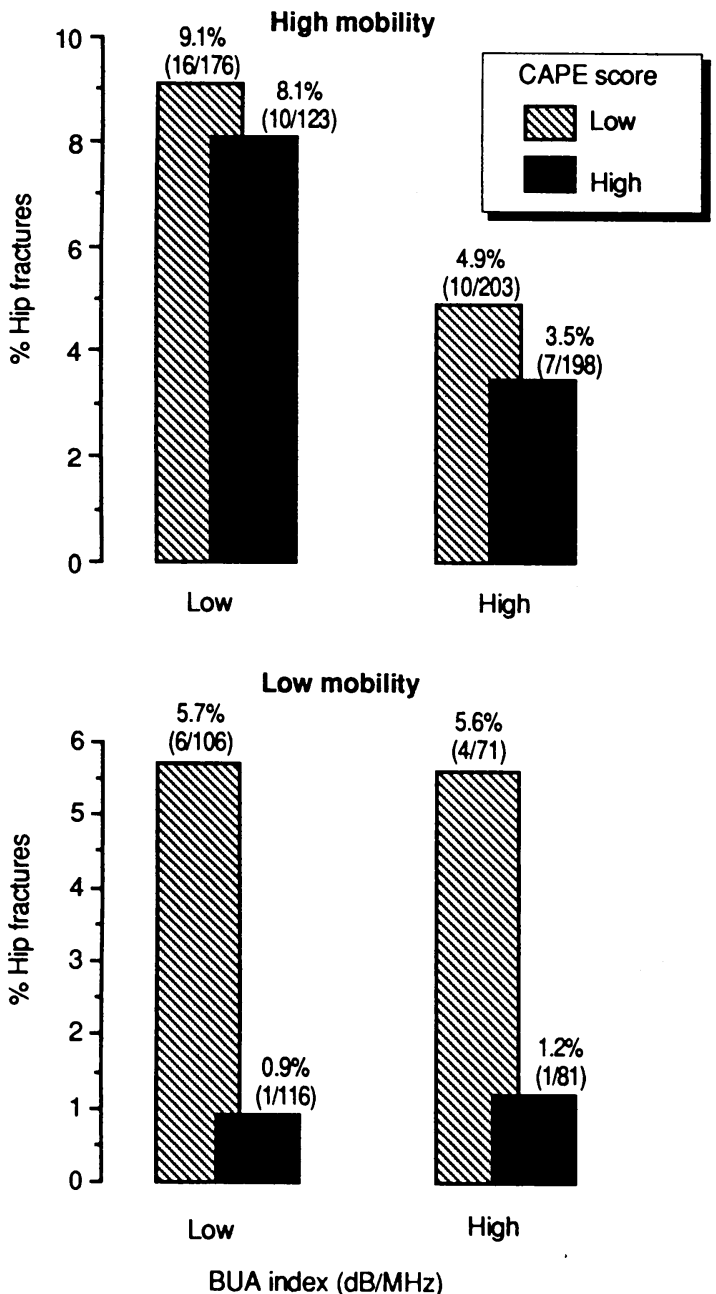

FIG 2-Incidence of hip fractures in women according to $B U A$ index, and CAPE test and mobility scores. (High, low scores are those above and below the median)

fracture $9 \cdot 1 \%$ ) had a low BUA index, low CAPE test score, and high mobility score whereas those with high CAPE test and low mobility scores had a low risk, irrespective of the BUA index (fig 2).

\section{Discussion}

A range of studies have shown a correlation between low density and low BUA index.$^{89}$ We wished therefore to test the ability of ultrasound testing to predict women in whom hip fracture will occur and also to examine other risk factors. Women from residential care were examined because of their accessibility and also bearing in mind our unreported observations that this is a population at high risk of hip fracture. The BUA index, which is used to assess osteoporosis, ${ }^{10}$ is well suited for examining many people in their place of residence, being portable, safe, simple, and radiation free. In contrast to other techniques that measure bone density, the BUA index is probably related not only to bone density but also to the architecture of bone, both important variables contributing to the overall strength of bone. The choice of the os calcis as the test site was supported by Wasnich $e t a l^{11}$ who reported that the os calcis is a good site for assessing the risk of osteoporotic fractures.

The BUA index of the women who sustained a hip fracture was significantly less than that of those who did not, most of the fractures occurring in the women in the lowest deciles of the index. Of the women in the lowest third of the index, $8.4 \%$ sustained a hip fracture in the two year period compared with $3.0 \%$ of the women in the upper third. Retrospective studies suggested a relation between low mineral density of bone and hip fracture, ${ }^{12-14}$ though its relative importance has been debated. ${ }^{5} 1516$ In this prospective study of elderly women in residential care, although there was an overlap between subpopulations that did and did not sustain a fracture, it was apparent that osteoporosis is an important factor associated with hip fracture.

The CAPE test score was also significantly different in the women who did and did not sustain a fracture $(\mathrm{p}<0.001)$. The differences were similar when the three parts of the test (information and orientation, mental ability, and psychomotor coordination) were examined separately, probably because they are interrelated. Poor cognisance and osteoporosis may share a common factor such as impaired nutrition, but in this study they were not significantly correlated and were independent variables.

In osteoporotic women (with a low BUA index) and those with poor cognisance (low CAPE test score) the incidence of fractures was $12.8 \%$, but in women with similar degrees of osteoporosis yet good cognisance it was only $3 \cdot 4 \%$ (fig 1 ). Women with poor cognisance probably had a propensity to fall, and this may be significant in relation to the incidence of hip fracture. It probably takes a fall for an osteoporotic woman to fracture the hip, and with good cognisance a fall is less likely. Similarly, in women with poor cognisance but good bone mass the rate of fractures was less than half that in those with poor bone mass $(6.2 v 12.8 \%$, fig 1$)$. A fall is less hazardous for a woman with good bone mass than for one with osteoporosis.

We found that the 73 women who fractured their hip were significantly more mobile than those who did not; many of the fractures occurred in osteoporotic women with poor cognisance who were very mobile. The less mobile women (with scores below median mobility score) with good cognisance (with scores above median CAPE test score) had a low incidence of fractures, irrespective of their BUA index (fig 2), perhaps because they were less likely to fall.

This study shows that in our population of elderly women in residential care two important factors for hip fracture were osteoporosis and cognisance and that they acted to some degree independently. The increasing age specific incidence of hip fracture ${ }^{1718}$ may be related to one or both of these factors. A subpopulation of women may exist who, because of their high mobility and poor cognisance, are at risk of falling, and who risk fracture if their BUA index is low.

It would be prudent in preventing hip fractures to consider the problem of poor cognisance in elderly people and to attempt to reduce the risk of falls by attention to eyesight ${ }^{19}$ and the environment. With the predicted half a million more people aged over 75 in the population before the end of the century, however, we 
need to deal with the problem of osteoporosis. Ideally, we should identify the most vulnerable women at the menopause and reduce the physiological decline in bone mineral, without undue risk to other systems. There is interest in ultrasound screening. ${ }^{20}$ Further studies may show that measurement of ultrasonic attenuation through the os calcis, although lacking the precision of low dose radiation techniques, may be able to identify women at greatest risk of later sustaining a hip fracture.

This study was made possible by the financial support of the Department of Health. We are grateful for the cooperation of the Department of Social Services; Yorkshire Regional Health Authority locally organised research scheme; the geriatricians, orthopaedic surgeons, and medical physics departments in Doncaster and Hull; and for the secretarial help of Mrs Jean Reynolds.

1 Royal College of Physicians. Fractured neck of femur. Prevention and management. London: RCP, 1989.

2 Bulstrode C. Keeping up with orthopaedic epidemics. Br Med f 1987;295:514 3 Cooper C, Barker DJP, Morris J, Briggs RSJ. Osteoporosis, falls, and age in fracture of the proximal femur. Br Med $\mathcal{F}$ 1987;295:13-5.

4 Consensus Development Conference. Prophylaxis and treatment of osteoporosis. Br Med F 1987;295:914-5.

Aitken JM. Relevance of osteoporosis in women with fracture of the femora neck. Br Med f 1984;288:597-601.
6 Langton C McD, Palmer SB, Porter RW. Measurement of broadband ultrasonic attenuation in cancellous bone. Eng Med 1984;13:89-91.

7 Porter RW, Johnson K, McCutchan JDS. Colles fracture, BUA and thoracic kyphosis. Bone (in press).

8 Pattie AH, Gilleard CJ. The two year predictive validity of the Clifton assessment schedule and the shortened Stockton geriatric rating scale. Brf Psychiatry 1978;133:457-60.

9 Palmer SB, Langton C McD. Ultrasonic studies of bone. London: Institute of Physics, 1987. (Short meetings series No 6).

10 Baran DT, Kelly AM, Karellas A, et al. Ultrasonic attenuation of the os calcis in women with osteoporosis and hip fractures. Calcif Tiss Int 1988;43. $138-42$

11 Wasnich RD, Ross PD, Heilbrun LK, Vogel JM. Selection of the optima skeletal side for fracture risk prediction. Clin Orthop 1987;216:262-8.

12 Cook PJ, Exton-Smith AN, Brocklehurst JC, Lempert-Barber SM. Fracture femur, falls and bone disorders. $\mathcal{F} R$ Coll Physicians Lond 1982;16:45-9.

13 Horsman A, Nordin BEC, Simpson M, Speed R. Cortical and trabecular bon status in elderly women with femoral neck fracture. Clin Orthop 1982;166: 143-51.

14 Cooper C, Barker DJP, Morris J, Briggs RSJ. Osteoporosis, falls and age in fracture of the proximal femur. Br Med 7 1987;295:13-5.

15 Sher JL, Aird EGA. A photon absorbtiometric estimation of bone minera content in the proximal femur. F Bone foint Surg [Br] 1983;65:660.

16 Boyce WJ. Osteoporosis, falls, and age in fracture of the proximal femur. BrMed f 1987;295:444-5.

17 Boyce WJ, Vessy MP. Rising incidence of fracture of the proximal femur. Lancet 1985;i:150-1.

18 Melton KLJ, O'Fallon WM, Riggs BL. Secular trends in the incidence of hip fractures. Calcif Tiss Int 1987;41:57.

19 Schapira AHV. Visual disability and the elderly. Time for general practitioners to begin preventive screening. Br Med F 1989;298:1126-7.

20 Anonymous. Ultrasound and bone fragility [Editorial]. Lancet 1989;ii:842.

(Accepted 10 fuly 1990)

\title{
Four and a half year follow up of women with dyskaryotic cervical smears
}

\author{
Astrid Fletcher, Nikki Metaxas, Chandra Grubb, Jocelyn Chamberlain
}

Department of Community

Medicine, University

College Hospital Medical

School, London

Astrid Fletcher, PHD, research fellow

Jocelyn Chamberlain, FRCP, senior lecturer

Joint Royal Free Hospital and University College Hospital Department of Cytology, London

Nikki Metaxas, MD, clinical assistant

Chandra Grubb, MRCPATH, director

Correspondence to: Dr A Fletcher, Epidemiology Research Unit, Division of Geriatric Medicine, Department of Medicine, Royal

Postgraduate Medical

School, London W12 0HS

BrMed f 1990;301:641-4 colposcopy - needs to be determined by randomised controlled trials.

Objective-Todetermine the proportion of women with mild or moderate dyskaryosis in cervical smears who $(a)$ progress to cervical intraepithelial neoplasia grade III or worse or $(b)$ regress.

Design-Four and a half year cytological follow up study of women with mild or moderate dyskaryosis in cervical smears.

Setting-A cytology laboratory in inner London.

Patients-666 Women (mean age 28 (SD 8) years; range 14-74) found to have borderline, mild, or moderate dyskaryosis on routine screening.

Results -45 Women $(6 \cdot 8 \%)$ had a cone biopsy recommended on the basis of an abnormal follow up smear (severe dyskaryosis suggestive of cervical intraepithelial neoplasia grade III or invasive cancer), and in one patient cervical intraepithelial neoplasia grade III was reported in a biopsy specimen after dilatation and curettage. Life table analysis gave a $14 \%$ probability of a patient being recommended for a biopsy after four and a half years of follow up $(\mathbf{9 5 \%}$ confidence interval $12 \%$ to $15 \%$ ). There was a significant excess incidence of invasive cancer of the cervix in the series compared with the general population (five cases observed compared with less than 0.1 expected). 157 Patients (24\%) showed reversion to a normal cell pattern sustained in several smears over more than 18 months but a single negative smear was an unreliable indicator of apparent regression. Having two successive smears showing mild dyskaryosis or a smear at any time showing moderate dyskaryosis was a significant predictor of a subsequent severely dyskaryotic smear.

Conclusions-Women found to have mild or moderate dyskaryosis in cervical smears should be kept under regular surveillance. The optimum management of these patients-by cytology or

\section{Introduction}

Guidelines have been published for the management of mild cervical intraepithelial abnormalities (cervical intraepithelial neoplasia grades I and II) detected in cervical smears ${ }^{1-3}$ Singer recommended colposcopy for all women with smears showing mild to severe cervical squamous dyskaryosis or malignant cells. ${ }^{1}$ Fox endorsed this approach but acknowledged that the extra burden on resources might not allow it. ${ }^{2}$ If immediate colposcopy was not available a repeat smear in three to six months was recommended with subsequent referral for colposcopy and biopsy for any dyskaryosis no matter how mild. Fox concluded: "Compromise is inevitable with inadequate colposcopy services in Britain, but compromise may sometimes mean death." The impetus for that comment was a report of 14 cases of cervical cancer in young women with previous dyskaryotic smears. ${ }^{3}$ Tragic as those cases were, however, they do not constitute the scientific evidence required for guidelines.

The report of the Intercollegiate Working Party on Cervical Cytology Screening also suggested colposcopy, ideally for all women with dyskaryotic smears but immediately for moderate dyskaryosis and after a further dyskaryotic follow up smear for mild dyskaryosis. ${ }^{4}$ Some contradictions were evident in that report, however, which suggested immediate colposcopy as an ideal but also stated that the optimum management of mild or moderate dyskaryosis was not known.

The outcome for patients with dyskaryotic smears is contentious. Studies have shown considerable variation in the proportions who seemed to show neoplastic progression or spontaneous reversion to normal and 